\title{
THE IMPORTANCE OF THE NATIVE LANGUAGE IN FOREIGN LANGUAGE LEARNING
}

\section{THE SYSTEM OF SIGNIFICANT SOUNDS}

\author{
David W. ReED \\ University of Michigan \\ in collaboration with
}

RoBert LAdo YaO SHEN
University of Michigan

1. Introduction. Foreign language teachers whose students have uniform native language backgrounds are apt not to realize that a given language cannot be successfully taught in an identical way to pupils of different language backgrounds. Nevertheless it is true that every different native language causes a different combination of problems in learning a given secondary language.

This is the first in a series of discussions of this general problem. The present article will be confined to problems arising from differences between the systems of significant sounds in the native language and the foreign language. Illustrations will be presented from the pronunciation problems encountered by speakers of Mandarin Chinese, Latin American Spanish, and Brazilian Portuguese in learning English. All problems involving non-significant differences in sounds, special combinations of sounds, accent, intonation, grammar, and vocabulary will be reserved for discussion in subsequent articles.

2. Phonemic charts.* For purposes of comparison, four charts of the significant sound segments of English, Chinese, Spanish, and Portuguese will provide a starting point:

* These are charts of the phonemic norms in the four languages. It should be noted that the same symbol is used for sounds that are often phonetically different in the various languages (e.g., $/ \mathrm{d} /$ ). Moreover sounds that are approximately the same phonetically may be classified differently according to the phonemic structure of the various languages (e.g., / $C /$ is a stop in English and Spanish, but an affricate in Chinese.) 


\begin{tabular}{|c|c|c|c|c|c|c|c|c|c|}
\hline \multicolumn{10}{|c|}{ ENGLISH (American) } \\
\hline & & \begin{tabular}{|l|} 
bi- \\
labial
\end{tabular} & $\begin{array}{l}\text { labio- } \\
\text { dental }\end{array}$ & $\begin{array}{l}\text { inter- } \\
\text { dental }\end{array}$ & $\begin{array}{c}\text { al- } \\
\text { veolar }\end{array}$ & $\begin{array}{c}\text { pala- } \\
\text { tal }\end{array}$ & \multicolumn{2}{|c|}{ velar } & glottal \\
\hline \multirow{2}{*}{ stops } & voiceless & $\mathrm{p}$ & & & $t$ & č & \multicolumn{2}{|c|}{$\mathbf{k}$} & \\
\hline & voiced & $\mathrm{b}$ & & & d & $\bar{y}^{1}$ & \multicolumn{2}{|c|}{$\mathbf{g}$} & \\
\hline \multicolumn{2}{|c|}{ nasals (voiced) } & $\mathbf{m}$ & & & $\mathbf{n}$ & & \multicolumn{2}{|c|}{$\mathrm{y}$} & \\
\hline \multirow{2}{*}{$\begin{array}{l}\text { frica- } \\
\text { tives }\end{array}$} & voiceless & & f & $\bar{\theta}$ & $\mathbf{s}$ & $\bar{\xi}=$ & & & $\bar{h}$ \\
\hline & voiced & & $\mathbf{v}$ & $\bar{\delta}$ & $\mathbf{z}$ & $\mathrm{Z}^{8}$ & & & \\
\hline \multicolumn{2}{|c|}{ lateral (voiced) } & & & & 1 & & & & \\
\hline & & & & & & front & central & back & \\
\hline \multicolumn{2}{|c|}{ semivowels } & & & & & $\mathbf{y}$ & $\mathbf{r}$ & $\mathbf{w}$ & \\
\hline \multirow{5}{*}{ vowels } & high & & & & & i & & $\mathbf{u}$ & \\
\hline & higher-mid & & & & & I & & $\overline{\mathbf{U}}$ & \\
\hline & mid & & & & & e & $\partial$ & o & \\
\hline & lower-mid & & & & & $\bar{\varepsilon}$ & & כ & \\
\hline & low & & & & & $\overline{\boldsymbol{Z}}$ & $a$ & & \\
\hline
\end{tabular}

\begin{tabular}{|c|c|c|c|c|c|c|c|}
\hline \multicolumn{8}{|c|}{ SPANISH (Latin American) } \\
\hline & & $\begin{array}{c}\text { bi- } \\
\text { labial }\end{array}$ & $\begin{array}{l}\text { Tabio- } \\
\text { dental }\end{array}$ & dental & $\begin{array}{c}\text { pala- } \\
\text { tal }\end{array}$ & \multicolumn{2}{|c|}{ velar } \\
\hline \multicolumn{2}{|c|}{ stops (voiceless) } & $\mathbf{p}$ & & $t$ & $\check{\check{c}}$ & \multicolumn{2}{|c|}{$\mathbf{k}$} \\
\hline \multicolumn{2}{|c|}{$\begin{array}{l}\text { stops or } \\
\text { fricatives (voiced) }\end{array}$} & b & & d & $\mathbf{y}$ & \multicolumn{2}{|c|}{$\mathbf{g}$} \\
\hline \multicolumn{2}{|c|}{ fricatives (voiceless) } & & $\mathbf{f}$ & $\mathbf{s}$ & & \multicolumn{2}{|c|}{$x$} \\
\hline \multicolumn{2}{|c|}{ nasals (voiced) } & $\mathrm{m}$ & & $\mathbf{n}$ & $\overline{\tilde{\mathbf{n}}}$ & & \\
\hline \multicolumn{2}{|c|}{ lateral (voiced) } & & & 1 & & & \\
\hline \multicolumn{2}{|c|}{ trill (voiced) } & & & $\tilde{\mathbf{I}}$ & & & \\
\hline \multirow{2}{*}{\multicolumn{2}{|c|}{ flap (voiced) }} & & & $\mathbf{r}$ & & & \\
\hline & & & & & front & central & back \\
\hline \multirow{3}{*}{ vowels } & high & & & & i & & $\mathbf{u}$ \\
\hline & mid & & & & $\mathbf{e}$ & & o \\
\hline & low & & & & & $\mathbf{a}$ & \\
\hline
\end{tabular}

${ }^{1}$ Because of difficulties in obtaining type / $\mathrm{d} z /$ has been substituted for this symbol in the text of the article. article. article.

$8 / z /$ has been substituted for this symbol in the text of the 


\begin{tabular}{|c|c|c|c|c|c|c|c|}
\hline \multicolumn{8}{|c|}{ CHINESE (Mandarin) } \\
\hline & & $\begin{array}{c}\mathbf{b i}- \\
\text { labial }\end{array}$ & $\begin{array}{l}\text { labio- } \\
\text { dental }\end{array}$ & dental & $\begin{array}{l}\text { retro- } \\
\text { flex }\end{array}$ & $\begin{array}{c}\text { pala- } \\
\text { tal }\end{array}$ & velar \\
\hline \multirow{2}{*}{ stops } & aspirated & $\mathrm{p}$ & & $\mathrm{t}$ & & & $\mathbf{k}$ \\
\hline & unaspirated & $\mathrm{b}$ & & $\mathrm{d}$ & & & $\bar{g}$ \\
\hline \multicolumn{2}{|c|}{ nasals (voiced) } & $\mathrm{m}$ & & $\mathbf{n}$ & & & $\eta$ \\
\hline \multirow{2}{*}{$\begin{array}{l}\text { affri- } \\
\text { cates }\end{array}$} & aspirated & & & $\mathbf{c}$ & $\bar{c}$ & $\bar{c}$ & \\
\hline & unaspirated & & & $\overline{\mathbf{j}}$ & $\bar{j}$ & $\bar{j} 1$ & \\
\hline \multicolumn{2}{|c|}{ fricatives (voiceless) } & & f & $\mathbf{s}$ & $\hat{\mathbf{s}}$ & $\xi^{2}$ & $\overline{\mathbf{h}}$ \\
\hline \multicolumn{2}{|c|}{ continuants (voiced) } & & & 1 & $\mathbf{r}$ & $\mathbf{y}$ & $\mathbf{w}$ \\
\hline \multirow{3}{*}{ vowels } & high & & & & & * & \\
\hline & mid & & & & & e & \\
\hline & low & & & & & $a$ & \\
\hline
\end{tabular}

\begin{tabular}{|c|c|c|c|c|c|c|c|}
\hline \multicolumn{8}{|c|}{ PORTUGUESE (Brazilian) } \\
\hline & & $\begin{array}{c}\text { bij } \\
\text { labial }\end{array}$ & $\begin{array}{l}\text { labio- } \\
\text { dental }\end{array}$ & dental & $\begin{array}{c}\text { pala- } \\
\text { tal }\end{array}$ & \multicolumn{2}{|c|}{ velar } \\
\hline \multirow{2}{*}{ stops } & voiceless & $\mathbf{p}$ & & $\mathbf{t}$ & & \multicolumn{2}{|c|}{$\mathbf{k}$} \\
\hline & voiced & b & & d & & \multicolumn{2}{|c|}{$\mathbf{g}$} \\
\hline \multicolumn{2}{|c|}{ nasals (voiced) } & $\mathbf{m}$ & & $\mathbf{n}$ & $\tilde{\tilde{\mathbf{n}}}$ & & \\
\hline \multirow{2}{*}{$\begin{array}{l}\text { frica- } \\
\text { tives }\end{array}$} & voiceless & & $\mathbf{f}$ & s & $\overline{S 2}^{2}$ & & \\
\hline & voiced & & $\mathbf{v}$ & $z$ & $\overline{2^{8}}$ & & \\
\hline \multicolumn{2}{|c|}{ laterals (voiced) } & & & 1 & $\overline{\boldsymbol{\Lambda}}$ & & \\
\hline \multicolumn{2}{|c|}{ trill (voiced) } & & & $\tilde{\tilde{\mathbf{\tau}}}$ & & & \\
\hline \multirow{2}{*}{\multicolumn{2}{|c|}{ flap (voiced) }} & & & $\mathbf{r}$ & & & \\
\hline & & & & & front & central & back \\
\hline \multirow{3}{*}{ vowels } & high & & & & $\bar{i}$ & & $\mathbf{u}$ \\
\hline & mid & & & & $\overline{\mathbf{e}}$ & & $\mathbf{0}$ \\
\hline & low & & & & $\bar{\varepsilon}$ & $\mathbf{a}$ & 2 \\
\hline
\end{tabular}

${ }^{1}$ Because of difficulties in obtaining type / dz / has been substituted for this symbol in the text of the article. article.

$2 / \int /$ has been substituted for this symbol in the text of the

$8 / z /$ has been substituted for this symbol in the text of the article. 
3. Difficulties common to the three language backgrounds. Examination of these charts will reveal that seven of the English sounds are not present as phonemes in any of the other languages $-/ \theta, \gamma$, $\mathrm{I}, \mathrm{U}, \partial, \varepsilon, \mathbb{x} / . \dagger$ For reasons that will be apparent in a moment the two sounds / $\delta, ~ ə /$ will be reserved for later discussion, while this section will consider the remaining sounds, which ordinarily cause the same difficulties for speakers of Chinese, Spanish, and Portuguese in learning English.

$/ \theta /$ is frequently pronounced as $/ \mathrm{s} /$; mispronunciations of thick may approximate English sick. beat.

$/ \mathrm{I} /$ is usually pronounced as $/ \mathrm{i} /$; therefore bit may sound like fool.

$/ \mathrm{U} /$ is frequently pronounced as $/ \mathrm{u} /$; hence full resembles

$/ \varepsilon /$ and $/ \Re /$ are mutually confused; pen and pan may sound virtually alike.

4. Difficulties common to two language backgrounds. A number of errors are common to speakers of two of the languages chosen for illustration.

4.1. Difficulties common to speakers of Chinese and Spanish. Students whose native language is Chinese or Spanish frequently make the same substitutions for five of the English sounds- $/ \delta$, $z, \supset, \mathfrak{a}, \mathrm{a} /$. Those substitutions are the following:

$/ \partial /$ is frequently pronounced as $/ \mathrm{d} /$; thus there may be pronounced so that it sounds more like dare.

$/ \mathrm{z} /$ is usually pronounced as $/ \mathrm{s} /$; mispronunciations of peas may approximate peace.

$/ \mathrm{o} /$ is frequently pronounced as $/ 0 /$; therefore caught may sound like coat.

$/ \mathfrak{a} /$ and / a / are mutually confused; add and odd may sound virtually alike.

4.2. Difficulties common to speakers of Spanish and Portuguese. Students whose native language is Spanish or Portuguese frequently make the same substitutions for the three additional English sounds $-/ d_{j}, h, \partial /$. These substitutions follow:

$\dagger$ English and Portuguese / $\varepsilon /$ are different enough phonetically to cause phonemic confusion. 
$/ \mathrm{d} z /$ is frequently pronounced as $/ \mathrm{z} /$; thus pledger may be pronounced so that it sounds more like pleasure.

/ h / is frequently not articulated (confused with "zero"); mispronunciations of hair may approximate air.

$/ \mathrm{a} /$ is usually pronounced as $/ \mathrm{a} /$ or as $/ \mathrm{o} /$; therefore $c u t$ may sound like cot or caught.

4.3. Difficulties common to speakers of Chinese and Portuguese. Students whose native language is Chinese or Portuguese often make the same sort of errors in pronouncing two additional English sounds $-/ \delta, \mathrm{v} /$.

$/ \delta /$ is frequently pronounced as $/ 2 /$; hence bathe resembles bays.

$/ \mathrm{U} /$ is frequently pronounced as $/ \partial /$; errors in pronouncing could may approach the sound of cud.

5. Difficulties peculiar to a single language background. The largest number of difficulties are peculiar to speakers of one of the three languages.

5.1. Difficulties peculiar to speakers of Chinese. Chinese students of English have special difficulties in pronouncing fourteen English phonemes- $/ \theta, \mathbf{v}, 1, \mathbf{r}, \mathbf{i}, \mathbf{u}, \mathrm{u}, \mathrm{e}, \mathfrak{x}, \mathrm{\partial}, \mathbf{0}, \varepsilon, \mathrm{\jmath}, \mathrm{a} /$.

$/ \theta /$ is often pronounced as $/ \mathrm{t} /$; thin may sound like $t$ in.

$/ \mathrm{v} /$ is often pronounced as $/ \mathrm{f} /$ or as $/ \mathrm{w} /$; veal may sound like feel or weal.

$/ 1 /$ and / r / are mutually confused; pull and poor may sound virtually alike.

$/ \mathrm{u} /$ is often pronounced as $/ \mathrm{U} /$ or as $/ 0 /$; pool may sound like pull or pole.

$/ \mathrm{i} /$ is often pronounced as $/ \mathrm{I} /$; beat may sound like bit.

$/ \mathrm{U} /$ is often pronounced as $/ \mathrm{o} /$; could may sound like code.

$/ \mathrm{e} /$ and $/ \mathfrak{x} /$ are mutually confused; ate and at may sound virtually alike.

$/ \partial /$ is often pronounced as $/ \varepsilon /$ or as $/ U /$; putt may sound like pet or put.

$/ 0 /$ is often pronounced as $/ \mathrm{u} /$, as $/ \mathrm{u} /$, or as $/ \mathrm{o} /$; pole may sound like pool, pull, or Paul.

$/ \varepsilon /$ is often pronounced as / a /; pet may sound like putt.

$/ \rho /$ and / a / are mutually confused; caught and cot may sound virtually alike. 
5.2. Difficulties peculiar to speakers of Spanish. Spanish-speaking students have special difficulties in pronouncing seven English phonemes-/b, v, d, dz, z, y, $\int /$.

/ b / and /v / are mutually confused; bale and veil may sound virtually alike.

$/ \mathrm{d} /$ is frequently pronounced as $/ \delta /$; den may sound like then.

$/ \mathrm{d} z / / \mathrm{z} /$, and $/ \mathrm{y} /$ are mutually confused; pledger and pleasure may sound virtually alike, as may jeer and year. cheer.

$/ \int /$ is frequently pronounced as $/ \check{c} /$; shear may sound like

5.3. Difficulties peculiar to speakers of Portuguese: Portuguesespeaking students have special difficulties in pronouncing eight English phonemes- $/ \check{c}, d_{z}, \theta, \succsim, h, r, y, w /$.

$/ \check{c} /$ is often pronounced as $/ \mathrm{d} z /$ or as $/ \int /$; chew may sound like Jew or shoe.

$/ \mathrm{d} z /$ is often pronounced as / $\check{c} /$; Jew may sound like chew.

$/ \theta /$ and $/ \delta /$ are mutually confused; ether and either may sound virtually alike.

/ h / and / r / are mutually confused; hose and rose may sound virtually alike.

$/ \mathrm{y} /$ and $/ \mathrm{w} /$ are mutually confused and frequently not pronounced at all (both confused with "zero"); year, we're, and ear may sound virtually alike.

6. Conclusion. The array of examples presented above may be synthesized by considering their meaning in terms of four situations in which English may be taught as a foreign language:

(1) Where all three language backgrounds are present in the students of one class, only five of the above difficulties are common to the whole group, and only ten of the difficulties are common to two of the language backgrounds; whereas twenty-nine of the difficulties are peculiar to one or another of the language backgrounds.

(2) Where students of Chinese and Portuguese language backgrounds are taught in the same class, only seven difficulties are common to the whole group, but twenty-two difficulties are peculiar to one or the other of the linguistic groups.

(3) Where students of Chinese and Spanish language backgrounds are taught in the same class, only ten difficulties are common 
to the whole group, but twenty-one difficulties are peculiar to one or the other of the linguistic groups.

(4) Where students of Spanish and Portuguese language backgrounds are taught in the same class, only eight difficulties are common to the whole group, but fifteen difficulties are peculiar to one or the other of the linguistic groups. (This may be startling to those who think Spanish and Portuguese are almost identical.)

Since in all of these cases the problems peculiar to speakers of one or another language are almost twice as numerous as the problems common to speakers of two or three languages, it would seem best whenever possible to teach the system of significant English sounds to classes having unified linguistic backgrounds. The effect of linguistic backgrounds on the learning of the finer points of pronunciation and of accent and intonation are not included in this discussion but will be treated in a subsequent article. When the number of students of a particular linguistic background is not sufficient to form a separate class to study the English phonemic system, it is nevertheless economical and efficient to have special materials prepared to meet the specific problems of the group.

\section{BIBLIOGRAPHY}

Bloomfield, Leonard, Language. New York, 1933. (Ch. 5, "The Phoneme," pp. 74-92.)

Hall, Robert A., Jr., "The Unit Phonemes of Brazilian Portuguese," Studies in Linguistics I, no. 15 (April, 1943).

- "Occurrence and Orthographical Representation of Phonemes in Brazilian Portuguese," Studies in Linguistics II, no. 1 (May 15, 1943).

Hartman, L. M., 3d, "The Segmental Phonemes of the Peiping Dialect," Language XX(1944), 28-42.

Karlgren, B., Etudes sur la phonologie chinoise. Leiden and Stockholm, 1915. Jones, Daniel, Outline of English Phonetics, 3d ed. Leipzig, 1932.

Kenyon, J. S., American Pronunciation. Ann Arbor, 1924.

Navarro Tomás, T., Manual de pronunciación española. Madrid, 1918. (English adaptation A. M. Espinosa, Primer of Spanish Pronunciation. New York, 1926.)

Reed, D. W., "The Segmental Phonemes of Brazilian Portuguese," in K. L. Pike, Phonemics. (In process of publication.)

Trager, G. L., "The Phonemes of Castilian Spanish," Travaux du Cercle Linguistique de Prague VIII (1939). 